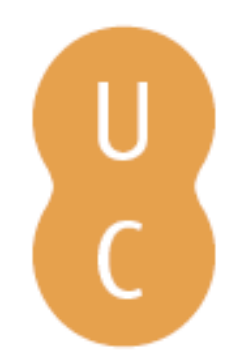

\title{
nommalina
}

\section{«Antígonas Antagónicas»: género, génio e a política de "performance» em Perdição e Florbela de Hélia Correia}

\author{
Autor(es): $\quad$ Owen, Hilary \\ Publicado por: Imprensa da Universidade de Coimbra \\ URL \\ persistente: URI:http://hdl.handle.net/10316.2/32318 \\ DOI: $\quad$ DOI:http://dx.doi.org/10.14195/978-989-26-0391-9_6 \\ Accessed : $\quad$ 26-Apr-2023 15:57:31
}

A navegação consulta e descarregamento dos títulos inseridos nas Bibliotecas Digitais UC Digitalis, UC Pombalina e UC Impactum, pressupõem a aceitação plena e sem reservas dos Termos e Condições de Uso destas Bibliotecas Digitais, disponíveis em https://digitalis.uc.pt/pt-pt/termos.

Conforme exposto nos referidos Termos e Condições de Uso, o descarregamento de títulos de acesso restrito requer uma licença válida de autorização devendo o utilizador aceder ao(s) documento(s) a partir de um endereço de IP da instituição detentora da supramencionada licença.

Ao utilizador é apenas permitido o descarregamento para uso pessoal, pelo que o emprego do(s) título(s) descarregado(s) para outro fim, designadamente comercial, carece de autorização do respetivo autor ou editor da obra.

Na medida em que todas as obras da UC Digitalis se encontram protegidas pelo Código do Direito de Autor e Direitos Conexos e demais legislação aplicável, toda a cópia, parcial ou total, deste documento, nos casos em que é legalmente admitida, deverá conter ou fazer-se acompanhar por este aviso.

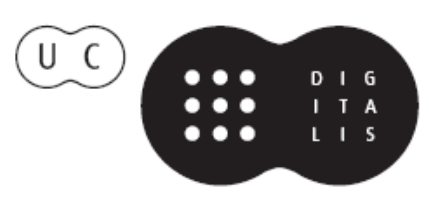


Maria de Fátima Sousa e Silva

Coordenação

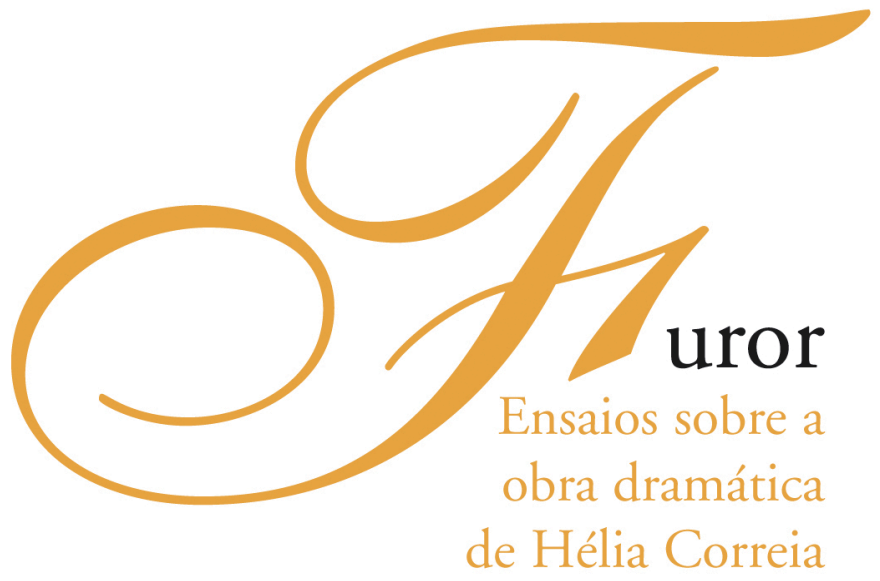

- COIMBra 2006 
COORDENAÇÃO EDITORIAL

Imprensa da Universidade de Coimbra

URL: http//www.imp.uc.pt

\author{
CONCEPÇÃO GRÁFICA \\ António Barros \\ PAGINAÇÃO \\ Inova \\ EXECUÇÃO GRÁFICA \\ Inova - Artes Gráficas \\ Porto
}

ISBN

972-8704-94-1

DEPÓSITO LEGAL

247166/06

C OUTUBRO, 2006, IMPRENSA DA UNIVERSIDADE DE COIMBRA

OBRA PUBLICADA COM O APOIO DE:

Centro de Estudos Clássicos e Humanísticos

FCT Fundação para a Ciência e a Tecnologia

MINISTÉRIO DA CIÊNCIA, TECNOLOGIA E ENSINO SUPERIOR Portugal 
Maria de Fátima Sousa e Silva

Coordenação

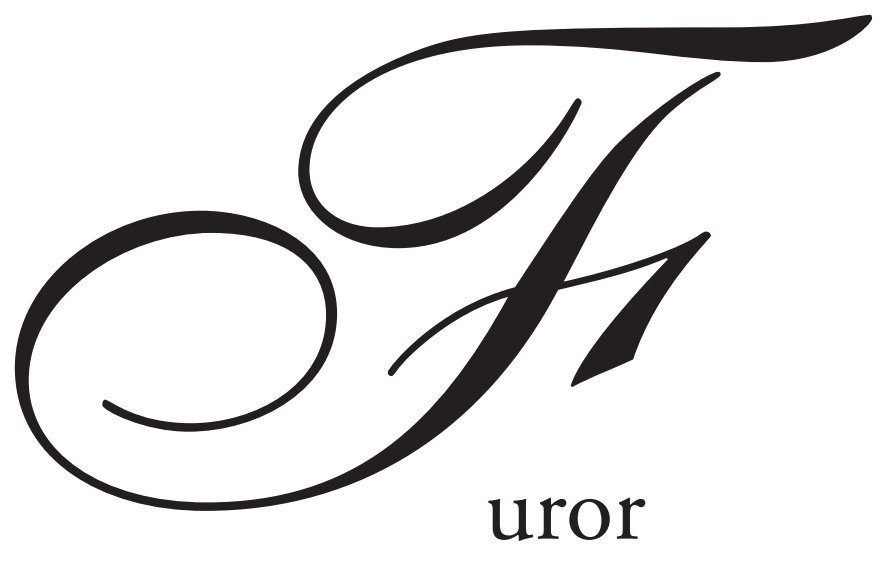

\author{
Ensaios sobre a \\ obra dramática \\ de Hélia Correia
}



Hilary Owen

Universidade de Manchester

\section{"ANTÍGONAS ANTAGÓNICAS»: GÉNERO, GÉNIO E A POLÍTICA DE «PERFORMANCE» EM PERDIÇÃO E FLORBELA DE HÉLIA CORREIA ${ }^{1}$}

For a male, art is already displaced sexuality; for a female it is already misplaced sexuality

(Battersby, p. 70).

Este nome "génio", sabemos muito bem que ele incomoda. De Fato. Há muito tempo. Com frequência tem-se razão em suspeitar nele uma abdicação obscurantista diante dos incómodos, justamente, uma concessão à genética do ingenium ou, pior, a um inatismo criacionista, em uma palavra, na linguagem de um outro tempo, a cumplicidade duvidosa de algum naturalismo biologizante e de uma teologia da inspiração extática (Derrida, pp. 8-9).

Numa palestra inédita dirigida «aos meus Professores do Curso de Pós-Graduação em Teatro Clássico», a escritora e dramaturga Hélia Correia afirma que «a minha Antígona é, com efeito, vergonhosamente actual. Desligou-se do cosmos e tudo o que ambiciona são os seus quinze minutos de glória».2 A Antígona que Hélia cria desvia-se, de facto em grande medida do original

\footnotetext{
1 Tradução do inglês por Hilary Owen e Vanessa Silva Pereira. Agradeço à Vanessa, como sempre, tanto a sua colaboração na tradução como as suas intervenções críticas.

${ }^{2}$ Ver "Perdição - exercício sobre Antígona. Uma composição acidental». Aos meus Professores do Curso de Pós - Graduação em Teatro Clássico da Faculdade de Letras de Coimbra. Inédito. Agradeço a Hélia Correia o ter-me disponibilizado o manuscrito desta palestra.
} 
sofocleano, e da sua oposição idealizada entre a lei do Estado e as leis da consanguinidade. Em vez de reabilitar o paradigma heróico do teatro clássico, Hélia opta por explorar o significado da brevidade da vida de Antígona, fazendo notar que relembra os "quinze minutos de glória» imortalizados por Andy Warhol no século XX. Esta reperspectivação permite-lhe uma análise dramática dos géneros sexuais e do ego feminino, numa família real tebana de cariz pós-moderno.

Outra obra de Hélia Correia que trata as mitologias da glória póstuma, do génio e da brevidade da vida, é a sua peça intitulada Florbela editada no mesmo volume que Perdição. Exercício sobre Antígona em 1991, embora as peças não fossem encenadas na mesma ocasião. Florbela estreou-se em 1991 e Perdição foi levada ao palco dois anos mais tarde em 1993. ${ }^{3}$ Várias leituras de Perdição neste volume (Maria de Fátima Sousa e Silva, Carmen Soares e Isabel Capeloa Gil) tratam, de diferentes formas, da importância de género nesta obra, mas fica ainda por realizar uma leitura comparativa de Perdição. Exercício sobre Antígona e Florbela que ponha em questão a influência do género na estruturação canónica do génio criativo. Conforme a contra-capa da primeira edição das duas peças, a própria Hélia Correia pergunta, "que haverá de comum entre Florbela e Antígona?» esboçando, desde logo, uma resposta provisória da seguinte forma:

Talvez o serem casos em que o aborrecimento inspirou grandeza? Suponhamos que Antígona não foi uma heroína, mas uma rapariga que tivera experiências violentas da vida e se viciou no gosto da pura insensatez. Florbela durou mais e escreveu versos. Mas parece também ter achado na morte o momento acabado da iluminação.

\footnotetext{
3 Perdição estreou-se com "A Comuna" em 1993 e Florbela foi encenada por "Maizum» em 1991 (Eugénia Vasques, p. 159).
} 
Na Antígona de Hélia Correia, a heroína teima em procurar uma morte prévia de tal maneira que a sua falência se assimila ao acto de puro suicídio que também caracteriza Florbela. Bem longe de resistir à lei do estado, a sua morte não reflecte senão um egoísmo niilístico e ambivalente que ultrapassa qualquer fronteira inteligível da vida. É esta análise do ego feminino em desenvolvimento abortivo que liga Perdição à mitologia suicida do génio que Hélia retoma e retoca na sua Florbela. Em contradição aberta com o original sofocleano, a Antígona de Hélia não expressa lealdade alguma em relação a Polinices, o irmão morto, que ela aliás sempre detestou. No limiar de se tornar uma mulher adulta, Antígona vê-se de facto aprisionada entre diferentes identificações sexuais, todas igualmente mórbidas e fatalistas. De modo paralelo, a auto-encenação (self-staging) realizada por Florbela Espanca na obra de Hélia, incorpora uma dramatização fluída da divisória que separa os géneros sexuais num terreno particularmente movediço, constituído pelas escuras origens familiares da escritora e pelas suas "poses» performativas e auto-conscientes perante a objectiva da câmara (e o público no teatro).

A minha leitura destas peças pretende descosturar a relação entre género sexual, leis simbólicas de consanguinidade, e construção mitológica de génio. Na minha análise, afirmo que em ambas as peças se evidenciam estratégias parecidas que são: a ruptura da temporalidade dramática linear e um descarrilamento das normas simbólicas do género. Estas estratégias acabam por desafiar a conceptualização do génio criativo como fenómeno do corpo masculino, mas sem proporem no seu lugar uma genealogia literária alternativa baseada na corporalidade feminina. Em vez disso, Hélia pergunta, em Perdição, de que forma as leis de consanguinidade conseguem definir e estabilizar as normas simbólicas do género sexual. Por extensão, em Florbela, a autora questiona de que forma estas leis de consanguinidade conseguem «naturalizar» os papéis de género que sustentam a canonização histórica do génio criativo conforme uma analogia familiar de paternidade e filiação. Assim, torna-se evidente que os nossos conceitos de "género" e "génio", além de serem construídos e representados numa "performance» em 
palco, também se representam e estruturam reciprocamente, reforçando assim, por meio da temporalidade teatral, tanto as estruturas normativas da consanguinidade na cultura como as das genealogias históricas do génio literário.

A obra Gender and Genius. Towards a Feminist Aesthetics da filósofa Christine Battersby é um dos pontos de referência fundamentais para este artigo. Battersby demonstrou como o Romantismo literário construiu um conceito da «sexualidade efeminada» para designar o génio artístico hipermasculino como algo estranho, estrangeiro ou forasteiro. Uma vez que esta construção romântica do génio artístico é orientada por uma energia criativa essencialmente masculina, dependerá necessariamente da exclusão do corpo da fêmea, isto é, do corpo material da mulher, da conceptualização do génio. Battersby alega que este processo é o responsável por um fenómeno misógino por ela designado como "escola da arte espermática» (p.70), presente de diferentes formas desde a Antiguidade até aos tempos pós-modernos. Esta autora afirma que as feministas, nos processos de escrita ou criativos, se devem centrar naquilo que pertence ao (sexo) feminino, à mulher material, "como sujeito que se encontra social e historicamente contextualizado por relações de poder. É então prematuro anunciar-se a morte da autora» (p.148). Embora admita que as reflexões de Battersby sobre a atribuição de um género ao génio são válidas no contexto das tradições literárias portuguesas, penso que a sua resposta de base essencialmente biológica (criar como [sexo] feminino), restringe várias possibilidades de análise, ao pressupor que a construção social que marca a diferença entre os géneros tem por base um critério de sexualidade essencializada.

A reacção das mulheres escritoras à exclusão que sofreram historicamente tomou, em Portugal, diferentes formas. De modo geral, no entanto, as escritoras recusaram a possibilidade de genealogias femininas baseadas numa diferença sexual absoluta. ${ }^{4}$ Graça Abranches sintetiza as várias formas de reacção na

\footnotetext{
4 A este respeito, escreveu Correia, «longe dos meus projectos estava escrever um texto de cariz feminista, o que sempre senti alheio por essência ao meu anti-sexismo". "Perdição - exercício sobre Antígona. Uma composição acidental”. Aos meus Professores do Curso de Pós-Graduação em Teatro Clássico da Faculdade de Letras de Coimbra».
} 
discussão que faz sobre a ausência de uma genealogia literária e tradição marcadamente femininas em Portugal, fazendo notar que:

A identificação com/o mulheres escritoras torna-se mais problemática na ausência de uma tradição [....]. A necessidade de procura, ou invenção, de outras genealogias ou tradições de escrita, vir-se-á a traduzir, então, quer no que Naomi Schor designou por uma intersexualidade mais estreita, com re-acentuações, re-valorizações ou subterrâneas interpelações mais marcadas da palavra masculina alheia, quer num diálogo mais íntimo com outras tradições literárias. ${ }^{5}$

Muitos dos argumentos históricos propostos por Batterby pressupõem a total eficácia e consistência da lei simbólica de Lacan e dos dualismos cartesianos clássicos de "matéria» ou "representação", "corpo» ou "mente», que orientam a percepção masculina de génio. Ou seja, «uma [mulher] criadora encontrava-se num dilema insuperável: ou entregava a sua sexualidade (não se tornando exactamente num macho mas num homem suplente), ou mantinha-se fêmea e feminina e, por isso, impossibilitava a sua inclusão na categoria de génio» (p. 3). Porém, se, como afirma Battersby, os campos lexicais relativos à «validação estética e à diferença sexual» (p. 6) estão intimamente relacionados, é importante relembrar, como já notámos acima, que estes dois campos lexicais actuam também reciprocamente um sobre o outro. Dito de outra forma, se o género sexual molda o génio, então os conceitos prevalecentes no génio criativo podem simultaneamente influenciar legítimas e validadas percepções de género e sexualidade. As afirmações canónicas da validação estética moldam os nossos conceitos da diferença sexual, e enfraquecem desta forma a diferença entre sexo e género na qual se baseiam os estudos de Battersby,

\footnotetext{
$\overline{5}$ Ver Graça Abranches, "Des-aprendendo para dizer: políticas, escritas e poéticas de mulheres portuguesas no século XX". Palestra inédita dada no Department of Spanish and Portuguese Studies, Universidade de Manchester. 23 de Abril de 1998, pp. 2-3.
} 
levando-nos, em vez disso, para as teorias de Judith Butler e à ruptura do binário «sexo/género» que faz parte da teoria queer.

Os estudos de Butler sobre o corpo sexualizado recusam qualquer existência material do corpo como essência primordial que pudesse existir fora das estruturas de referência, significação e representação, que constroem o corpo retroactivamente como se fosse "natural", após ser nomeado e referido pelo discurso. Para Butler então, a forma como o corpo fica conbecido torna-se mais importante do que como o corpo é. Na sua obra crítica, Antigone's Claim. Kinship between Life and Death, Butler debruça-se precisamente sobre a questão do género e da genealogia nas mitologias de Antígona na literatura ocidental, refutando especificamente as interpretações de Lacan. Este estudo proporcionanos um quadro desconstrutivo de grande valor para descrever as subversivas posições textuais e subtextuais que se encontram disponíveis para as mulheres escritoras como resposta ao dilema de "incorporação/descorporalização" que subjaz à história sexuada do conceito de "génio». O modelo pós-estruturalista de Butler enfatiza uma constante reiteração «performativa» das divisórias do género sexual, impossibilitando paulatinamente dessa forma qualquer distinção que se pretendesse «absoluta». Na minha análise, estas «reiterações performativas» desempenham um papel fulcral na luta subterrânea que a mulher criadora trava contra a masculinização do génio criativo.

De acordo com uma das várias etimologias possíveis sugeridas por Butler e as suas fontes, o nome Antígona provém do grego «anti/gone» o que significa "contra geração» (Butler, p. 22). Assim a Antígona Butleriana representa a quinta essência de uma corporalidade perdida, abortada, optando por ser emparedada viva por ter sepultado o irmão, e abandonando a vida sem se realizar como mãe. Mas Butler, como Hélia, aproveita a resistência de Antígona, não como modelo de oposição a Polis, mas como modelo de exagero excessivo que extravasa e desnaturaliza o simbólico e cujo efeito seria principalmente irónico. Para Butler, a veemência reiterada da famosa tomada de posição de Antígona acaba por fissurar e minar as identidades familiares e sexuais que, no original 
sofocleano, Antígona parece defender. Neste caso, então, o desejo proibido que a Antígona clássica sente pelo irmão que sepulta, e a sua resistência masculinizada ao rei Creonte, constituem «a ruptura com a lei que se afirma precisamente no acto de se reinstituir essa mesma lei» (Butler p. 66). ${ }^{6}$ A repetição teimosa de Antígona assinala uma aberração da lei simbólica que expõe a fragilidade e a fractura constantemente inerentes aos termos dessa mesma lei.

A peça Florbela responde, em grande medida, à lei masculinizada do cânone português, sustentado por estruturas referenciais que permitem a inteligibilidade das diferenças naturalizadas do corpo sexual, e que foram transmitidas através das gerações por tradições literárias de [homens] escritores e historiografias literárias paternalistas. Por esta razão, Florbela lida com a criatividade feminina no contexto dos condicionalismos do cânone masculino, que se impõe como a "lei simbólica» que governa o "corpo» da escrita feminina. Assim, a minha abordagem ao género e génio no teatro de Hélia Correia centra-se, essencialmente, nas suas afirmações irónicas e repetidas da descorporalização feminina e da morte do corpo da mulher/mãe criativa. Esta abordagem centra-se nas posturas "performativas» que Antígona e Florbela adoptam citando e espelhando, num sentido lúdico, as tradições e convenções de género recebidas dos cânones dos [homens] escritores.

A encenação de Perdição. Exercício sobre Antígona toma a forma de uma representação visual da dualidade "incorporação contra a descorporalização», dividindo tanto a página no texto como o espaço em palco em duas categorias, os «Vivos» e as "Mortas». Desta maneira, Perdição exige um «olhar duplo» do espectador. O profeta hermafrodita Tirésias opera num terceiro plano, comentando os acontecimentos e ligando os dois mundos, de uma posição mediática que se vê espelhada na transição de Antígona e da sua ama, que estão a fazer uma travessia entre os dois mundos. Se Tirésias tenta profetizar o futuro, a Antígona

\footnotetext{
$\overline{6}$ No original inglês, "a breaking from the law that takes place in the reinstituting of the law» (Butler, p. 66).
} 
morta reflecte retrospectivamente sobre a vida da Antígona viva, comentando as suas escolhas e os seus significados, enquanto viaja ao Hades na companhia da sua fiel ama. Assim o espectador/leitor experimenta, tanto visual como textualmente, a «vida-na-morte» que foi o destino de Antígona emparedada viva. Além disso, os comentários de Antígona revelam a sua desorientação temporal e indicam um certo "deslize» entre as zonas temporais da "vida» e da "morte». A acção que testemunhamos em palco é duplamente «especularizada» já que o público vê a Antígona morta no processo de esta se observar a si mesma ainda em vida.

Focando as razões que podem explicar o desafio de Antígona, em vez de procurar o significado universal do acto em si mesmo, a peça salienta a sua falta de aderência rígida e completa a qualquer papel sexual ou familiar, enfatizando as relações ténues que estabelece com outras mulheres e a sua recusa de uma qualquer incorporação material como «mulher». Tendo perdido a sua mãe «biológica» Jocasta, Antígona foi criada pela ama e pela tia Eurídice, a esposa de Creonte. A Antígona viva é alvo de várias desilusões desde o início da sua vida. A passividade cúmplice da irmã Isménia, o maternalismo excessivo da tia Eurídice, e o tédio da vida feminina em geral, reduzem as mulheres que conhece a esposas traídas e parideiras contínuas, espezinhadas pelo regime patriarcal grego. Antígona compreende demasiado bem que a sua vida há-de ser passada neste espaço restrito para mulheres, no "gineceu». Da sua perspectiva de morta, ela comenta, "conheci a pequena alegria das mulheres. O cinto com o fecho onde brilha uma jóia. Uma coroa de junquilhos no cabelo» (p. 33). Consciente de que as esposas reais, como a sua tia, nunca auferem independentemente do prazer carnal, uma vez que os maridos dormem com as suas criadas, Antígona apercebe-se de que a única alternativa deixada às mulheres consiste em participar nos rituais dionisíacos clandestinos, num espaço abjecto, fora da cultura. A sua ama e a sua tia confirmam esta suspeita quando reafirmam que Antígona não tem nada a esperar da sua vida futura, mesmo que se decida a vivê-la: "fica uma vida filha entre os teares, o armazém e a lareira» (p. 34). 
Por conseguinte, Antigona vê-se, em memória do seu pai, inexoravelmente atraída pela vida militar masculina. A sua decisão de morrer, trazida pela sua oposição a Creonte, deve ser encarada como uma recusa fatalista do casamento, e da vida familiar reprodutiva, postos à sua disposição pelo primo e pretendente Hémon. O acto de enterrar o irmão Polinices, a quem ela sempre de facto detestou, acontece mais ou menos por acaso, servindo só de pretexto para confrontar Creonte. Antígona rejeita ainda qualquer possibilidade de perdão ou fuga que lhe é proposta, para poder, em vez disso, abraçar a morte como a única forma possível de expressar o seu ego no espaço público, provocando assim, como Butler nota, "a ruptura com a lei que se afirma precisamente no acto de se reinstituir essa mesma lei» (Butler, p. 66).

Os comentários retrospectivos da Antígona morta mostram-se, no entanto, menos nítidos e decisivos. A Antígona morta descreve-se a si mesma, em vida, como uma «rapariguinha alucinada» (p. 56). As dúvidas da Antígona morta vêem-se refletidas no arrependimento da Antígona viva que pergunta à sua ama, «eu não conseguiria viver com eles, suportar aquela paz...?» (p. 57). Ela fracassa na sua tentativa de comunicar a si própria que tudo foi um erro, dizendo «é preciso que ela ouça e compreenda. Este campo de flores nauseabundas é tudo o que há depois...» (p. 57). Como a ama lhe relembra, é tarde demais para mudar seja o que for, dizendo, «não vês que estás aqui? Que já aconteceu» (p. 57). A sua opção pelo suicídio é posta em questão quando a Antígona morta afirma que, em comparação com a morte, «é bem preferível a vida miserável das mulheres» (p. 57). Ao mesmo tempo interroga-se sobre o valor do ego masculino que havia tentado usurpar e que descreve, sob a forma de um intertexto pessoano, como «sonhos que não valem a pena» (p. 57). Nem uma nem outra identificação de género lhe proporcionam qualquer espaço onde possa, literalmente, arranjar uma vida.

Finalmente, Antígona fica suspensa, como se fosse emparedada, no seu próprio texto entre «vivos» e «mortas». É um nome mítico que codifica para toda a eternidade a ausência (a impossibilidade) do corpo feminino falar no 
discurso da Lei Lacaniana. Por esta razão, o seu diálogo com a ama acaba da mesma maneira como começou, com uma breve memória física e afectiva de algo vivo, a cadelita que teve que deixar, antes de se esvaecerem para sempre os seus últimos vestígios de vida. O seu inconformismo sexual toma a forma de uma polarização incompleta, a "vida-na-morte», representada como um espaço de auto-reflexão reiterativa que acaba por enfraquecer a própria lei de divisão que exige esta polaridade sexual.

É o adivinho hermafrodito Tirésias que tem a última palavra no drama, pondo fim ao eco reiterativo da temporalidade dupla e do espaço duplo na encenação. Como Hélia afirma na sua análise de Perdição, Tirésias «dá por finda a idade dos mágicos», anunciando o fim da intervenção divina na vida dos humanos, o fim da comunicação entre vivos e mortos, impondo afinal a clausura simbólica da lei edipiana que inaugura a cultura. ${ }^{7}$ A maldição contra os filhos de Édipo vê-se finalmente cumprida, com o destino póstumo de Antígona na mitologia literária. O corpo hermafrodito de Tirésias, embora divinamente castigado, possui ainda materialidade e direito à fala, dom este que ele aproveita para criar o distanciamento épico e heróico na sua última referência a Antígona como símbolo universal, eterno, neutro e sem corporalidade, da ousadia tentada e falhada de toda a humanidade a "perguntar-se como teria sido se ousassem e perdessem. Como a pequena Antígona» (p. 58). Entretanto, a própria Antígona espelha a bissexualidade corpórea de Tirésias ao inverso, situando-se num entre-lugar sexual, sem género nem sexo. Silenciada pela impossibilidade de qualquer vida corpórea que seja sua, Antígona torna-se no objecto épico/heróico, inscrito na mitologia literária pelo génio criativo do

\footnotetext{
7 Ver Correia, "Perdição - exercício sobre Antígona. Uma composição acidental». Aos meus Professores do Curso de Pós-Graduação em Teatro Clássico da Faculdade de Letras de Coimbra». "Pois a tragédia pessoal de Antígona, a agonia de Creonte, de Hémon e das mulheres coincidem com a maior de todas as tragédias, com a tragédia que resulta do abandono do divino pelos humanos e da retirada dos que desempenhavam o papel de intermediários com o cosmos vivo. Tirésias anuncia que, a partir de então, os adivinhos, os xamãs, os derviches, todos os magos se retirarão, deixando os homens inteiramente sós».
} 
homem profeta e excepcional. Desta forma, a «insexabilidade» desta Antígona desconstrutiva acaba por ser finalmente emparedada viva na lei simbólica e naturalizada de Lacan, no texto ainda masculinamente bissexual que é o génio feito homem. Como Isabel Capeloa Gil afirma, " a construção a três planos permite o cruzar das fronteiras do espaço, mas não a alteração dos lugares, dos sexos, dos poderes que a aporia da morte acaba por consagrar». Portanto, a estratégia reiterativa, auto-referencial e «citational» que Hélia aproveita neste tempo/espaço duplo (ou seja, a Antígona que tenta assumir a masculinidade à qual se opõe na figura de Creonte), consegue desmascarar e pôr em questão a impossibilidade de géneros/sexos fluídos e alternativos dentro da cultura como sistema ainda inteligível.

Como acontece com Perdição, Florbela também se centra numa mulher «excepcional» e no desenvolvimento do seu ego auto-criativo na esfera pública. Hélia representa a descorporalização sexual de Florbela como uma constante auto-reiteração simultaneamente presenciada pela objectiva da câmara e pelo público no teatro. Como a Antígona de Correia, Florbela recria a sua própria vida e a sua imortalidade literária desde a perspectiva da sua morte. Um catafalco com o corpo desenterrado de Florbela está presente ao longo da peça como pano de fundo. O drama depende, ainda mais que Perdição, de uma série de diálogos que Florbela, como criança e como adulta, conduz com uma figura designada apenas por "guia», uma mulher anónima, idosa mas sem idade, que existe entre-sexos e entre-papéis, desempenhando por turnos o papel de crítica, espectadora, alterego e ama, relembrando a ama de Antígona. Como a didascália refere, esta guia é «claramente inumana [...] deve ter a androgenia dos anjos, porque é um Anjo, e a memória do feminino porque é o Guia de uma mulher» (p. 61). A guia informa Florbela da imagem póstuma que esta possui e do destino das suas obras no cânone crítico da literatura portuguesa. O sentido da descorporalização, experimentada por Florbela, é retratado na desconjuntura que a guia revela entre a imagem que Florbela cria para si (mudando obsessivamente de roupa, de voz, de persona em palco) e a sua recriação mítica e controversa 
aos olhos da história literária. Deste modo, a simbolização sexual de Florbela torna-se no ponto fulcral da discussão na qual ela intervém para expor a exclusão do corpo feminino relativamente ao simbólico masculino. Como Christine Battersby sublinhou, "for a male, art is already displaced sexuality; for a female it is already misplaced sexuality" (p. 70). Assumindo o direito de resposta à sua própria construção pelo cânone português como "aberração sexual", Florbela exerce um notável poder de ruptura em relação à autoridade crítica. Tal como no caso de Antígona, a sua ambiguidade sexual provém, em grande medida, da sua história genealógica que foi difusa e pouco convencional.

Como Antígona, nascida das relações entre o seu pai/irmão e Jocasta, a mãe do pai, a genealogia de Florbela põe em questão as convenções de consanguinidade. Esta confessa que a sua genealogia foi uma obra de ficção, uma falsificação da família "legítima». Florbela era filha de uma criada que praticamente desconhecia, engravidada pelo pai, através de um acordo tácito, justificado pela infertilidade da sua esposa legítima. Apeles, o irmão de Florbela, foi concebido da mesma forma, pelo mesmo pai todo-poderoso cujo patronímico é, mais tarde, adoptado por Florbela, embora seja omitido, por sinal, do nome desta peça que se intitula simplesmente Florbela. A Florbela de Correia diz que passou a infância "livre de amor materno» (p. 76). A sua linhagem fictícia e o seu estatuto de «ilegítima» fomentam fantasias extravagantes que também permitem a sua auto-identificação fora dos limites ditos "naturais» e impostos pela consanguinidade familiar. Constantemente retratada pelo pai fotógrafo, ela assume conscientemente o papel do «ideal» feminino e especularizado, construindo para si mesma, em palco, uma fantasia descorporalizada e supra-sexual.

Assim disfarçada, adopta "poses» icónicas contestando a sua construção pelo cânone masculino. Falando desta posição, opõe-se às instituições críticas dos homens, aqui representadas por Jorge de Sena, que a chama de "poeta" e não de "poetisa", o que provoca a seguinte pergunta: "querem fazer de mim um homem, já agora?!». Retomando os fios desta ambivalência sexual, a guia 
comenta que Florbela e seu irmão Apeles formam juntos a figura dupla e auto-reprodutiva de «um ser hermafrodita» (p. 89), sem separação nítida entre os géneros. Repetindo o destino de Antígona, morrendo jovem, por suicídio e sem filhos, Florbela associa a sua falta de maternidade com a imagem idealizada e espiritual de consanguinidade familiar que ela concretiza nas suas fantasias em relação a Apeles, afastando-se da materialidade "grosseira» do corpo material. Desta maneira, o seu irmão torna-se num "filho» idealizado que esta reconhece quando diz: «eu fui mãe de Apeles. Conheci nele uma espiritual maternidade. Parir um filho de qualquer dos meus maridos seria entrar definitivamente na vulgaridade dos mortais» (p. 83). Como Antígona, Florbela sente aversão pela sua própria incorporação feminina e vê na sua natalidade materna (o facto de ter provindo do útero mortal de uma mulher) uma maldição. Matando a mãe simbólica, prefere imaginar-se procriada, tanto intelectual como divinamente, por agência exclusiva do seu pai. Neste sentido, Florbela descreve-se a si mesma como «uma deusa, nascida na espuma de seu pai. Porque o meu nascimento se passou sem mulheres. [...] Eu fui Palas Atena, nascida de uma ideia, do excesso de personalidade de João Espanca. Ele precisava de se desdobrar, de extravasar de si [...] Tudo emana do meu pai» (p. 75). Esta fantasia partenogénica da criação da mulher escritora pelo pai remonta também à imagem de hermafroditismo que a ligava ao irmão/amante/filho Apeles, por quem ela se manteve apaixonada ao longo da vida. Por isso, representa-se o seu suicídio como consequência da morte de Apeles num acidente de avião, tragédia que despoleta a dependência fatal de Florbela de barbitúricos. Suicidou-se no seu aniversário em 1930 tendo já anunciado no seu diário, «eu estava a separar-me do corpo nessa altura» (p. 95), despindo, nesse momento, finalmente o disfarce corporal e feminino que a mantinha presa e lhe impossibilitava o génio.

Fingindo conscientemente as poses de uma mulher criativa mórbida, sexualmente aberrante e histérica, citando e recitando os seus próprios poemas, e assim reiterando-se irónica e postumamente perante o espelho duplo do público teatral e da objectiva da câmara, Florbela mimetiza de forma 
propositadamente exagerada, inexacta e controversa todas as camadas históricas de estereótipo que lhe foram sendo impostas pela posteridade literária. A Florbela de Correia contesta as provocações da guia (que lê em voz alta diversas críticas negativas) para afirmar o seu génio como o inverso desconstrutor do génio postiço e oco representado pelo cânone masculino, citando expressamente a negação do seu génio por Jorge de Sena e a sua tentativa de a excluir do panteão literário que viria a integrar Mário de Sá Carneiro, Fernando Pessoa, Camilo Pessanha e José Régio. Fazendo da sua própria "misplaced sexuality" um tecido dramático e "citational» de auto-imagens e textos recontextualizados, Florbela consegue desestabilizar a autoridade do génio masculino. Repetindo e reinstituindo as leis simbólicas e absolutas que governam a canonização paternalista para demonstrar as suas falhas inerentes, esta personagem ergue um "ego criativo", inverso da sua exclusão, no vazio performativo entre o corpo morto no catafalco e o corpo vivo, mas duplo, de "Florbela» mítica e entre aspas, falando com a sua guia. Desta forma, Florbela consegue um certo distanciamento épico em relação a si mesma, posição que foi monopolizada por Tirésias na conclusão de Perdição.

Nestas duas peças, o destino aparentemente inalterável das duas (anti)heroínas abre um espaço "performativo» reiterativo, revisionista e recursivo, desfazendo qualquer cronologia absoluta e fechada, e ao mesmo tempo desfazendo a lei simbólica do género nos seus próprios termos. Impossibilita-se, assim, a sujeição total e definitiva da "Mulher» como outro Lacaniano, ao facto criativo do eu masculino. Liberta-se o seu corpo fictício e imaginado sem o converter numa "Contra-incorporação» maternalista. Tanto Antígona como Florbela aproveitam as suas reiterações funerárias para «desreconhecer» e «estranhar» o próprio «eu» incorporado e carnal, assim transformando a "aberrância» sexual numa força produtiva e, ao mesmo tempo, negando as imagens negativas e fatalistas associadas ao ego criativo no feminino. A ironia inerente a esse "duplo negativo" expõe e desarticula a dicotomia clássica que opõe a imagem da mulher como «ausência de corpo» à visão da mulher como «excesso de cor- 
po", mito que se limita a universalizar o poder procriativo do homem como sendo a «base natural» da lei simbólica do génio, que se reproduz pseudo-geneticamente nas genealogias canónicas. É esta "performatividade» do ego

feminino criador que expõe a "performatividade» igualmente fictícia do "génio" do homem, disfarce mutável e retórico que depende da diferença absolutista dos sexos para o sustentar, mas cujo calcanhar de Aquiles reside precisamente ali, como Butler sublinha, na "ruptura com a lei que se afirma precisamente no acto de se reinstituir essa mesma lei» (p. 66).

\section{Bibliografia}

Abranches, Graça. «Des-aprendendo para dizer: políticas, escritas e poéticas de mulheres portuguesas no século XX». Palestra inédita. Research Seminar do Department of Spanish and Portuguese Studies, Universidade de Manchester. 23 de Abril de 1998.

Battersby, Christine. Gender and Genius. Towards a Feminist Aesthetics. London: The Women's Press, 1989.

Butler, Judith. Antigone's Claim. Kinship Between Life and Death. New York: Columbia UP, 2000.

Correia, Hélia. Perdição. Exercício sobre Antígona. Florbela. Lisboa: Dom Quixote, 1991.

Correia, Hélia. "Perdição - exercício sobre Antígona. Uma composição acidental». Aos meus Professores do Curso de Pós - Graduação em Teatro Clássico da Faculdade de Letras de Coimbra.» Palestra inédita.

Derrida, Jacques. Gêneses, genealogias, gêneros e o gênio. Trad. Eliane Lisboa. Porto Alegre: Editora Sulina, 2005.

Gil, Isabel Capeloa. "Espectros literários: Perdição de Hélia Correia.» Actas do Sexto Congresso da Associação Internacional de Lusitanistas. Rio de Janeiro. 1999.

http://www.geocities.com/ail_br/espectrosliterarios.html Consultado a 26 de Abril de 2006. 
Sophocles, The Three Theban Plays. Trans. Robert Fagles. Introd. and Notes. Bernard Knox. Harmondsworth: Penguin, 1984.

Vasques, Eugénia, Mulheres que Escreveram Teatro em Portugal no Século XX. Lisboa: Colibri, 2001. 



\section{Série}

\section{Documentos}

Imprensa da Universidade de Coimbra

Coimbra University Press

2006

- $\mathrm{U}$

C • 